\title{
Falling Short of the First 90: HIV Stigma and HIV Testing Research in the 90-90-90 Era
}

\author{
Matthew C. Sullivan ${ }^{1} \cdot$ Aviana O. Rosen $^{1} \cdot$ Aerielle Allen ${ }^{1} \cdot$ Diane Benbella $^{1} \cdot$ Gabriel Camacho $^{1}$. \\ Andrew C. Cortopassi ${ }^{1} \cdot$ Redd Driver $^{1} \cdot$ Jude Ssenyonjo ${ }^{1}$. Lisa A. Eaton ${ }^{1} \cdot$ Seth C. Kalichman ${ }^{1}$
}

Published online: 6 January 2020

(c) Springer Science+Business Media, LLC, part of Springer Nature 2020

Despite great strides forward, several countries are far from achieving the goals of the UNAIDS 90-90-90 initiative, aimed toward identifying and diagnosing $90 \%$ of people living with HIV, distributing antiretroviral therapy (ART) to $90 \%$ of people diagnosed, and achieving viral suppression in $90 \%$ of people receiving treatment. HIV stigma is likely a contributing factor in failing to achieve these goals, particularly the first 90 -identifying and diagnosing $90 \%$ of those infected. Since the 2014 launch of the 90-90-90 initiative, major advances in global access to ART have culminated in half of the world's people living with HIV now receiving treatment [1]. There has also been marked progress in the infrastructure needed to distribute HIV treatments worldwide [1, 2]. However, treating HIV starts with diagnosing HIV, making the first 90 the critical cornerstone in efforts to end HIV epidemics. Shortfalls in achieving 90\% HIV diagnoses are apparent throughout sub-Saharan Africa, where the vast majority of the world's HIV infections are concentrated [3]. In some countries with the most devastating HIV epidemics, progress has been slowest in achieving the first 90 [3]. In 2017 an estimated 76\% of people with HIV in this region had been diagnosed, $79 \%$ of whom were receiving ART, and $83 \%$ of those receiving ART had achieved HIV suppression. These averages, however, mask the disparities that exist among countries. HIV stigma is most certainly one of numerous factors at play in failing to achieve the first 90 .

HIV stigma is a ubiquitous and pervasive barrier to every point along the HIV continuum of care [4-7]. Societal

Electronic supplementary material The online version of this article (https://doi.org/10.1007/s10461-019-02771-7) contains supplementary material, which is available to authorized users.

Seth C. Kalichman

seth.k@uconn.edu

1 The Institute for Collaboration on Health, Intervention, and Policy (InCHIP), University of Connecticut, Storrs, CT, USA devaluation of people with HIV and intersecting characteristics, such as gender, sexual orientation and substance use, adds to the burden of receiving an HIV diagnosis [8]. Prejudice, stereotypes, and discrimination against people living with HIV create a social context in which personal concerns for safety, a sense of shame, social exclusion and other adverse social conditions accompany the prospect of receiving a positive HIV test [9]. Harsh structural expressions of HIV stigma, particularly criminalization of HIV, can also undermine efforts to scale-up HIV testing [10]. People who endorse prejudicial attitudes towards people living with HIV are themselves less likely to accept HIV testing [6]. Having witnessed discriminatory acts and other forms of enacted stigma leads to expectations or anticipation of stigma following an HIV diagnosis. Anticipating future stigma is linked to lower rates of testing uptake in multiple populations [8, 11-13].

Having not achieved the 90-90-90 targets in any country with a substantial HIV epidemic, we asked to what degree may stigma be impeding HIV testing? We therefore took a cursory look at the state of research on the role of stigma in HIV testing in sub-Saharan Africa. We examined published studies between 2014 and 2019 that reported on the relationship between HIV stigma and HIV testing. We purposefully selected the African countries with the highest HIV prevalence by total population: South Africa, Nigeria, Mozambique, Kenya, Tanzania, Uganda, Zimbabwe, Zambia, and Malawi [14]. Together, these nine countries are home to an estimated 20.1 million people living with HIV. We did not set out to conduct a comprehensive review. Rather, this Editorial is intended to provide a thumbnail sketch of research on the relationship between HIV stigma and HIV testing in high-HIV prevalence countries to inform the next steps toward achieving the 90-90-90 targets. 


\section{The State of the Literature on HIV Stigma and HIV Testing in Sub-Saharan Africa}

Relevant publications were searched in PubMed in March of 2019, with independent searches for each of the nine countries. We used combined free-text search terms "HIV" AND "test" AND "stigma" AND [name of country]. We only reviewed studies published between 2014 and 2019, the 90-90-90 era, that measured HIV stigma in relation to HIV testing uptake. We only included studies that directly assessed stigma and uptake of HIV testing, omitting policy analyses, studies of HIV testing experiences, studies of stigma experiences in people living with HIV as well as other studies that fall outside of stigma in relation to testing. Studies that sampled participants across countries were included if they reported results individually for each country. We collected qualitative, quantitative, and mixed-method studies. A detailed summary of the studies we examined, country by country, is reported as electronic supplementary material. Below we briefly summarize the state of research for each country.

\section{South Africa}

Our search yielded 18 studies conducted in South Africa, encompassing both quantitative and qualitative studies of varying size, scope, and designs. Stigma was consistently identified as a barrier to HIV testing across a diverse range of participants. Of five studies that included quantitative measures of stigma [6,15-18], three used stigma scales that had previously been used in South Africa. Perceived stigma and discrimination were found to vary across study populations, with higher rates of stigma and overt discrimination occurring in socioeconomically disadvantaged urban and rural communities relative to betterresourced settings [19-22]. With respect to HIV testing, women tended to report more frequent testing than men, with men often indicating hesitation to attend primary health clinics due to concern that they may be perceived as less masculine [23, 24]. Two large quantitative surveys, however, reported conflicted findings with regard to gender, stigma and HIV testing. One study of young adults showed a strong negative relationship between perceived HIV stigma and testing in women but not in men, while another study in urban commuters showed a negative relationship between perceived stigma and testing in men but not in women [21, 23]. In contrast to most findings, one study showed that women who held more stigmatizing attitudes regarding people living with HIV were more likely to report having been HIV tested [21]. Concerns regarding breaches of confidentiality about test results by health care providers were a common source of hesitancy to get tested, particularly among men. Other themes regarding the impact of stigma on testing included perceived risks for social ostracism, loss of primary romantic relationships, and employment discrimination [22, 25]. As such, a number of studies indicated greater acceptability of hometesting or self-testing than facility-based testing, especially among men [22, 25-27].

\section{Tanzania}

Next to South Africa, the greatest amount of HIV stigmaHIV testing research was reported from Tanzania, with 13 studies published since 2014. Results consistently suggest that HIV testing uptake has increased in Tanzania among both men and women. Nevertheless, stigma remains a key barrier to achieving optimal testing rates. Among women, stigma is experienced across multiple contexts, including community members, family, and healthcare professionals [28-30]. Studies find that integrating HIV testing services with antenatal care may shield potential stigma by disguising the type of services being sought. However, women receiving antenatal services still reported fear of testing positive as a barrier $[28,30]$. Among men, research in Tanzania has focused primarily on stigma in social networks as potential barriers to HIV testing. One study found that making HIV testing appear more normative may reduce stigma and increase men's HIV testing [31]. Another study found that peer support that encouraged testing reduced anticipated stigma among male peers and community members and resulted in higher testing uptake [32].

\section{Nigeria}

Published research regarding stigma and HIV testing remains scant in Nigeria, as our search found only four studies, all of which implicated stigma as a barrier to HIV testing [33-36]. Two quantitative studies with men who have sex with men (MSM) found that sexual orientation stigma served as a barrier to HIV testing and healthcare utilization [33, 34]. One cohort of men found that stigma derived from the passage of laws prohibiting same-sex marriage and fear of judgements for engaging in same-sex relations were linked to poor engagement in HIV testing among Nigerian MSM [33]. Another study of men involved in exchange sex found that fear, public harassment, and the experience of sexual violence were associated with low testing uptake [34]. A qualitative study among pregnant women and their male partners indicated that fear and shame of being diagnosed with HIV and its subsequent impact on family functioning 
inhibited HIV testing [35]. Furthermore, testing hesitation resulted from anticipating HIV stigma from family and the community, triggering concerns about losing social support and being abandoned [34].

\section{Mozambique}

Only four studies examined barriers to HIV testing in Mozambique, and all found an association between low-testing rates and stigma [36-39]. Two studies were conducted exclusively in Mozambique, and the other two examined testing throughout several African countries, including Mozambique. A multi-country study by Fleming et al. was specifically conducted to provide insight into the barriers to reaching 90-90-90 goals [36-38]. Fleming et al. found that approximately $35 \%$ of men aged 15-49 endorsed stigmatizing views of people with HIV, and these men were significantly more likely to report never testing for HIV. The other three studies found stigma to be the among the most pervasive barriers to testing [36-39]. However, in Mozambique stigma was a robust barrier to HIV testing for women but not men, suggesting that other factors may impede testing for men over and above stigma, such as access to health services and masculinity [36, 38].

\section{Kenya}

Eight studies conducted research on the impact of stigma as an impediment to HIV testing in Kenya [39-44]. Results showed that women tested more frequently than men, despite holding more stigmatizing attitudes towards people living with HIV [40]. In a multi-country study discussed above, Fleming et al. found that Kenyan men who endorsed more stigmatizing attitudes towards people living with HIV were less likely to have tested for HIV [39]. In addition, Nyblade et al. [41] reported that female sex workers who anticipated stigma from their healthcare provider were more likely to avoid HIV testing. Similar concerns were expressed among university students, adolescents, and young adults [44-46]. Romo et al. found a similar effect among long distance truck drivers, where anticipated stigma was associated with lowrates of HIV testing [42].

\section{Uganda}

In Uganda, only four studies evaluated stigma as an impediment to HIV testing [36, 40, 47, 48]. The limited amount of research on stigma and testing in Uganda was surprising given the decades of focused attention this country has received in research. All of the studies we found confirmed stigma as a barrier to HIV testing. Like other countries in the region, the relationship was stronger among women than men, suggesting that men may encounter additional barriers contributing to their low HIV testing rates. In rural communities, both men and women greatly underestimated the number of persons tested, and that those who perceived testing as less normative were less likely to have been tested [47].

\section{Zimbabwe}

Four studies examined the associations between HIV-related stigma and HIV testing in Zimbabwe [39, 49-51]. Each study found that HIV stigma was associated with lower likelihood of HIV testing. Studies in both men and recent mothers found that those who held prejudicial views of people with HIV were less likely to have ever been tested for HIV [39, 49]. A longitudinal qualitative study interviewed participants embedded within the multi-national Project Accept community-level randomized trial intended to reduce HIV-related stigma, increase HIV testing, and reduce HIV infections [50, 51]. While participants identified stigma as a cause of low HIV testing for women in antenatal care, results also suggested decreases overtime in stigmatizing attitudes. In particular, decreases were observed in blaming people with HIV as well as fearing casual contact with those who have HIV infection.

\section{Zambia}

Three qualitative and one quantitative study assessed the impact of stigma on HIV testing in Zambia [39, 52-54]. A large survey using population-based data found a negative relationship between endorsing HIV-related prejudice and HIV testing in men [39]. A qualitative study identified anticipated stigma from healthcare workers and peers as a barrier to testing in female sex workers [52]. One study of midwives examined their perspectives of why male partners of pregnant women do not participate in the prevention of mother-to-child transmission of HIV or HIV testing [53]. Midwives cited stigma from healthcare services, society, and other individuals as barriers to men's testing. However, another study found that men themselves denied that anticipated stigma was a barrier to testing in Lusaka, but instead reported that self-stigma did impede testing [54]. Similarly, healthcare workers and lay counsellors reported that shame and self-stigma were experienced by people with HIV. These data suggest that stigma remains a primary barrier to testing in Zambia, although it remains unclear which types of stigma inhibit testing. 


\section{Malawi}

Results from three studies in Malawi suggest that structural support may play an important role in the relationship between stigma and HIV testing [39, 49, 55]. For instance, one study found that prejudicial attitudes towards people living with HIV predicted lower odds of lifetime HIV testing in young mothers. However, this association was no longer significant after controlling for whether mothers were offered antenatal HIV testing [49]. In another study utilizing a national dataset, HIV prejudice was associated with higher odds of never having been tested for HIV among men. Although structural factors were not considered in further models, the association between stigma and testing remained significant when other factors were considered, including HIV-related knowledge and acceptance of gender-based violence [39, 55]. Findings in Malawi suggest that it is the experience of going to testing sites that deters testing among men, who prefer home testing [55].

\section{Conclusions}

Our admittedly cursory review found 62 studies examining the relationship between HIV stigma and HIV testing in nine African countries representing among the highest HIV prevalence in the world. A majority of the research was conducted in two countries, South Africa and Tanzania. This startling dearth of research is perhaps the major finding from our review. We did not observe any change in the number of annually published studies over the years representing the first phase of the 90-90-90 initiative. The studies varied in methodological quality and used a wide range of self-report instruments to measure HIV-related stigma. Quantitative studies ranged from large multinational surveys including tens of thousands of participants, to smaller survey studies and studies using single-item or idiosyncratic stigma measures $[19,26,39]$. The qualitative research also varied, with studies examining stigma across heterogeneous populations, using a variety of methods that included focus groups, participant observation, and in-depth individual interviews [25, 42, 56]. Only two studies reported data from research designed to evaluate interventions to reduce the impact of stigma as a barrier to HIV testing [51, 57].

Stigma manifests differently across populations, with differing forms of stigma conferring uneven HIV testing uptake. Sex workers, both female and male, experience exceptionally high-rates of overt discrimination, with sex workers in several countries reporting experiences of stigma from healthcare workers, breaches of confidentiality, and delay or denial of HIV testing services [28, 34, 41, $43,48]$. Men who have sex with men also report high-rates of verbal harassment and anticipated discrimination, leading to avoidance of health care as well as concealment of sexual history during health visits $[33,34,58]$. Healthcare workers themselves endorse HIV-related stigma as a barrier to testing, although this stigma appears to be subtle. For example, although few healthcare workers in one study anticipated overt workplace discrimination on the basis of having tested HIV positive, over a third nevertheless believed that very few of their coworkers would want to be aware of their HIV status [19].

The limited amount of research we reviewed did elucidate avenues to address HIV stigma among men and women. First, men were more likely to endorse prejudicial attitudes towards people living with HIV than women across countries, and prejudicial attitudes were shown to be associated with a lower likelihood of engaging in HIV testing in both men and women [39, 40]. HIV testing norms also appeared to be an especially influential correlate of men's testing behavior, with low perceived social support for testing posing a major obstacle [31,32]. Qualitative research suggests that for men, the prospect of receiving an HIV diagnosis is associated with fears of discrimination and loss of material resources through lost employment, rejection from family and community, and threats to masculinity [24, 59]. Women also anticipated stigma reactions from their partners in response to an HIV diagnosis; with some women reluctant to test or ask partners to test due to concerns that their partners may force them to leave their home based on the test results [37].

The studies we examined show a need for a research agenda on adverse social conditions driven by stigma that impede HIV testing. This research agenda should go beyond descriptive studies, which represent the majority of those conducted thus far in the 90-90-90 era. One conclusion that is so obvious it can go without saying is that there is far more data on HIV stigma than there is HIV stigma theory. And while theory alone will carry little public heath meaning, a stronger conceptual grounding will go a long way toward promoting higher quality research to inform interventions. Longitudinal studies are needed to identify mechanisms and points of intervention. Studies that examine stigma in social relationships using dyadic, community, and multi-level models are needed. Methods are needed to harmonize data from multiple stigma measures. A stigma research agenda should also advance our measurement and knowledgebase of intersectional stigma, specifically the unique experience of stigma faced by individuals with multiple stigmatized characteristics. Research on stigma and testing should also be extended to stigma as an impediment to HIV prevention, including 
pre-exposure prophylaxis (PrEP). This Editorial should not be mistaken as a comprehensive review. Indeed, systematic reviews and meta-analyses will be critical to advancing a research agenda on HIV stigma and testing. Publishing quality original research on HIV stigma and testing will remain a high priority at AIDS and Behavior.

Funding Preparation of this Editorial was supported by a training grant from the National Institute of Mental Health T32-MH074387.

\section{References}

1. UNAIDS. Global HIV \& AIDS statistics-2018 fact sheet 2018. http://www.unaids.org/en/resources/fact-sheet.

2. World Health Organization. Policy brief: Consolidated guidelines on HIV prevention, diagnosis, treatment and care for key populations. World Health Organization; 2017.

3. UNAIDS. Ending AIDS: progress towards the 90-90-90 targets 2017. http://www.unaids.org/en/resources/documents/2017/20170 720_Global_AIDS_update_2017.

4. Kharsany AB, Karim QA. HIV infection and AIDS in sub-Saharan Africa: current status, challenges and opportunities. Open AIDS J. 2016;10:34-48.

5. Chesney MA, Smith AW. Critical delays in HIV testing and care: the potential role of stigma. Am Behav Sci. 1999;42(7):1162.

6. Kalichman SC, Simbayi LC. HIV testing attitudes, AIDS stigma, and voluntary HIV counselling and testing in a black township in Cape Town, South Africa. Sex Transm Infect. 2003;79(6):442-7.

7. Bond V, Chase E, Aggleton P. Stigma, HIV/AIDS and prevention of mother-to-child transmission in Zambia. Eval Program Plan. 2002;25(4):347-56.

8. Mahajan AP, Sayles JN, Patel VA, Remien RH, Ortiz D, Szekeres G, et al. Stigma in the HIV/AIDS epidemic: a review of the literature and recommendations for the way forward. AIDS. 2008;22(Suppl 2):S67.

9. Earnshaw VA, Chaudoir SR. From conceptualizing to measuring HIV stigma: a review of HIV stigma mechanism measures. AIDS Behav. 2009;13(6):1160.

10. Lehman JS, Carr MH, Nichol AJ, Ruisanchez A, Knight DW, Langford AE, et al. Prevalence and public health implications of state laws that criminalize potential HIV exposure in the United States. AIDS Behav. 2014;18(6):997.

11. Earnshaw VA, Smith LR, Chaudoir SR, Amico KR, Copenhaver MM. HIV stigma mechanisms and well-being among PLWH: a test of the HIV stigma framework. AIDS Behav. 2013;17(5):1785-95.

12. Golub SA, Gamarel KE. The impact of anticipated HIV stigma on delays in HIV testing behaviors: findings from a community-based sample of men who have sex with men and transgender women in New York City. AIDS Patient Care STDS. 2013;27(11):621-7.

13. Stall R, Hoff C, Coates TJ, Paul J, Phillips KA, Ekstrand M, et al. Decisions to get HIV tested and to accept antiretroviral therapies among gay/bisexual men: implications for secondary prevention efforts. JAIDS J Acquir Immune Defic Syndr. 1996;11(2):151-60.

14. Central Intelligence Agency. World factbook country comparison: people living with HIV/AIDS 2016. https://www.cia.gov/library/ publications/the-world-factbook/fields/364rank.html.

15. Berger BE, Ferrans CE, Lashley FR. Measuring stigma in people with HIV: psychometric assessment of the HIV stigma scale. Res Nurs Health. 2001;24(6):518.
16. Kalichman SC, Simbayi LC, Jooste S, Toefy Y, Cain D, Cherry $\mathrm{C}$, et al. Development of a brief scale to measure AIDS-related stigma in South Africa. AIDS Behav. 2005;9(2):135-43.

17. Pitpitan EV, Kalichman SC, Eaton LA, Cain D, Sikkema KJ, Skinner D, et al. AIDS-related stigma, HIV testing, and transmission risk among patrons of informal drinking places in Cape Town, South Africa. Ann Behav Med. 2012;43(3):362-71.

18. Visser MJ, Makin JD, Vandormael A, Sikkema KJ, Forsyth BW. HIV/AIDS stigma in a South African community. AIDS Care. 2009;21(2):197-206.

19. Khan R, Yassi A, Engelbrecht MC, Nophale L, van Rensburg AJ, Spiegel J. Barriers to HIV counselling and testing uptake by health workers in three public hospitals in Free State Province, South Africa. AIDS Care. 2015;27(2):198-205.

20. Haffejee F, Maughan-Brown B, Buthelezi T, Kharsany AB. Perceived HIV-related stigma among university students in South Africa: implications for HIV testing. Afr J AIDS Res. 2018;17(2):109-18.

21. Maughan-Brown B, Nyblade L. Different dimensions of HIVrelated stigma may have opposite effects on HIV testing: evidence among young men and women in South Africa. AIDS Behav. 2014;18(5):958-65.

22. Martinez Perez G, Cox V, Ellman T, Moore A, Patten G, Shroufi A, et al. 'I Know that I Do Have HIV but Nobody Saw Me': oral HIV self-testing in an informal settlement in South Africa. PLoS ONE. 2016;11(4):e0152653.

23. Chimoyi L, Tshuma N, Muloongo K, Setswe G, Sarfo B, Nyasulu PS. HIV-related knowledge, perceptions, attitudes, and utilisation of HIV counselling and testing: a venue-based intercept commuter population survey in the inner city of Johannesburg, South Africa. Glob Health Action. 2015;8(1):26950.

24. Mambanga P, Sirwali RN, Tshitangano T. Factors contributing to men's reluctance to seek HIV counselling and testing at primary health care facilities in vhembe district of South Africa. Afr J Prim Health Care Fam Med. 2016;8(2):e1-7.

25. Nkosi B, Seeley J, Ngwenya N, McHunu SL, Gumede D, Ferguson $\mathrm{J}$, et al. Exploring adolescents and young people's candidacy for utilising health services in a rural district, South Africa. BMC Health Serv Res. 2019;19(1):195.

26. Nkuna E, Nyazema NZ. HIV self-testing, self-stigma and Haart treatment at the University of Limpopo: health sciences students' opinion and perspectives. Open AIDS J. 2016;10:78-82.

27. Orne-Gliemann J, Zuma T, Chikovore J, Gillespie N, Grant M, Iwuji C, et al. Community perceptions of repeat HIV-testing: experiences of the ANRS 12249 treatment as prevention trial in rural, South Africa. AIDS Care. 2016;28(Suppl 3):14-23.

28. Beckham SW, Shembilu CR, Brahmbhatt H, Winch PJ, Beyrer C, Kerrigan DL. Female sex workers' experiences with intended pregnancy and antenatal care services in southern Tanzania. Stud Fam Plan. 2015;46(1):55-71.

29. An SJ, George AS, LeFevre A, Mpembeni R, Mosha I, Mohan $\mathrm{D}$, et al. Program synergies and social relations: implications of integrating HIV testing and counselling into maternal health care on care seeking. BMC Public Health. 2015;15(1):24.

30. Wallace A, Kimambo S, Dafrossa L, Rusibamayila N, Rwebembera A, Songoro J, et al. Qualitative assessment of the integration of HIV services with infant routine immunization visits in Tanzania. J Acquir Immun Defic Syndr. 2014;66(1):e8.

31. Yamanis TJ, Dervisevic E, Mulawa M, Conserve DF, Barrington C, Kajula LJ, et al. Social network influence on HIV testing among urban men in Tanzania. AIDS Behav. 2017;21(4):1171-82.

32. Conserve DF, Alemu D, Yamanis T, Maman S, Kajula L. "He Told Me to Check My Health": a qualitative exploration of social network influence on Men's HIV testing behavior and HIV self-testing willingness in Tanzania. Am J Men's Health. 2018;12(5):1185-96. 
33. Schwartz SR, Nowak RG, Orazulike I, Keshinro B, Ake J, Kennedy $S$, et al. The immediate effect of the Same-Sex Marriage Prohibition Act on stigma, discrimination, and engagement on HIV prevention and treatment services in men who have sex with men in Nigeria: analysis of prospective data from the TRUST cohort. Lancet HIV. 2015;2(7):e299-306.

34. Crowell TA, Keshinro B, Baral SD, Schwartz SR, Stahlman S, Nowak RG, et al. Stigma, access to healthcare, and HIV risks among men who sell sex to men in Nigeria. J Int AIDS Soc. 2017;20(1):21489.

35. Ehiri JE, Iwelunmor J, Iheanacho T, Blackstone S, Obiefune MC, Ogidi AG, et al. Using a cultural framework to understand factors influencing HIV testing in Nigeria. Int Q Commun Health Educ. 2016;37(1):33-42.

36. Gunn JK, Asaolu IO, Center KE, Gibson SJ, Wightman P, Ezeanolue EE, et al. Antenatal care and uptake of HIV testing among pregnant women in sub-Saharan Africa: a cross-sectional study. J Int AIDS Soc. 2016;19(1):20605.

37. De Schacht C, Hoffman HJ, Mabunda N, Lucas C, Alons CL, Madonela A, et al. High rates of HIV seroconversion in pregnant women and low reported levels of HIV testing among male partners in Southern Mozambique: results from a mixed methods study. PLoS ONE. 2014;9(12):e115014.

38. Paulin HN, Blevins M, Koethe JR, Hinton N, Vaz LM, Vergara $\mathrm{AE}$, et al. HIV testing service awareness and service uptake among female heads of household in rural Mozambique: results from a province-wide survey. BMC Public Health. 2015;15(1):132.

39. Fleming PJ, Rosen JG, Wong VJ, Carrasco MA. Shedding light on a HIV blind spot: factors associated with men's HIV testing in five African countries. Glob Public Health. 2019;1:1-11.

40. Gebregziabher M, Dai L, Vrana-Diaz C, Teklehaimanot A, Sweat M. Gender disparities in receipt of HIV testing results in six SubSaharan African countries. Health Equity. 2018;2(1):384-94.

41. Nyblade L, Reddy A, Mbote D, Kraemer J, Stockton M, Kemunto $\mathrm{C}$, et al. The relationship between health worker stigma and uptake of HIV counseling and testing and utilization of non-HIV health services: the experience of male and female sex workers in Kenya. AIDS Care. 2017;29(11):1364-72.

42. Romo ML, George G, Mantell JE, Mwai E, Nyaga E, Odhiambo $\mathrm{JO}$, et al. Psychosocial characteristics of primary care-seeking long-distance truck drivers in Kenya and associations with HIV testing. Afr J AIDS Res. 2018;17(2):119-28.

43. Shangani S, Naanyu V, Mwangi A, Vermandere H, Mereish E, Obala A, et al. Factors associated with HIV testing among men who have sex with men in Western Kenya: a cross-sectional study. Int J STD AIDS. 2017;28(2):179-87.

44. Mwangi R, Ngure P, Thiga M, Ngure J. Factors influencing the utilization of Voluntary Counselling and Testing services among university students in Kenya. Glob J Health Sci. 2014;6(4):84.

45. Wilson KS, Beima-Sofie KM, Moraa H, Wagner AD, Mugo C, Mutiti PM, et al. "At our age, we would like to do things the way we want:" a qualitative study of adolescent HIV testing services in Kenya. AIDS. 2017;31(Suppl 3):S213.

46. Nall A, Chenneville T, Rodriguez LM, O'Brien JL. Factors affecting HIV testing among youth in Kenya. Int J Environ Res Public Health. 2019;16(8):1450.
47. Perkins JM, Nyakato VN, Kakuhikire B, Mbabazi PK, Perkins HW, Tsai AC, et al. Actual versus perceived HIV testing norms, and personal HIV testing uptake: a cross-sectional, populationbased study in rural Uganda. AIDS Behav. 2018;22(2):616-28.

48. Wanyenze RK, Musinguzi G, Kiguli J, Nuwaha F, Mujisha G, Musinguzi J, et al. "When they know that you are a sex worker, you will be the last person to be treated": perceptions and experiences of female sex workers in accessing HIV services in Uganda. BMC Int Health Hum Rights. 2017;17(1):11.

49. Chung AH, Rimal RN. Applying choice architecture principles to understand HIV testing: findings from Malawi and Zimbabwe. AIDS Educ Prev. 2015;27(4):362-72.

50. Gazimbi MM, Magadi MA. Individual- and community-level determinants of antenatal HIV testing in Zimbabwe. J Biosoc Sci. 2019;51(2):203-24.

51. Maman S, van Rooyen H, Stankard P, Chingono A, Muravha T, Ntogwisangu J, et al. NIMH Project Accept (HPTN 043): results from in-depth interviews with a longitudinal cohort of community members. PLoS ONE. 2014;9(1):e87091.

52. Chanda MM, Perez-Brumer AG, Ortblad KF, Mwale M, Chongo $\mathrm{S}$, Kamungoma N, et al. Barriers and facilitators to HIV testing among Zambian female sex workers in three transit hubs. AIDS Patient Care STDS. 2017;31(7):290-6.

53. Auvinen J, Kylmä J, Välimäki M, Bweupe M, Suominen T. Midwives' perspectives on male participation in PMTCT of HIV and how they can support it in Lusaka, Zambia. Midwifery. 2014;30(1):17-27.

54. Musheke M, Merten S, Bond V. Why do marital partners of people living with HIV not test for HIV? A qualitative study in Lusaka, Zambia. BMC Public Health. 2016;16(1):882.

55. Rankin-Williams AC, Geoffroy EM, Schell ES, Mguntha AM. How can male rates of HIV testing be increased? Recommendations from a mixed methods study in southern Malawi. Int Health. 2017;9(6):367-73.

56. Hallonsten S. "No More Buzz": a qualitative study of the current response to HIV in the Anglican Church in the Western Cape, South Africa. J Relig Health. 2017;56(4):1201-11.

57. Weihs M, Meyer-Weitz A, Baasner-Weihs F. The influence of lotteries on employees' workplace HIV testing behaviour. Afr J AIDS Res. 2018;17(1):9-21.

58. Ross MW, Nyoni J, Ahaneku HO, Mbwambo J, McClelland RS, McCurdy SA. High HIV seroprevalence, rectal STIs and risky sexual behaviour in men who have sex with men in Dar es Salaam and Tanga, Tanzania. BMJ Open. 2014;4(8):e006175.

59. Chikovore J, Gillespie N, McGrath N, Orne-Gliemann J, Zuma $\mathrm{T}$. Men, masculinity, and engagement with treatment as prevention in KwaZulu-Natal, South Africa. AIDS Care. 2016;28(Suppl 3):74-82.

Publisher's Note Springer Nature remains neutral with regard to jurisdictional claims in published maps and institutional affiliations. 